\title{
EVALUASI PELAKSANAAN PROGRAM PWMP DI SMKPP NEGERI MATARAM
}

\author{
Sugiarta ${ }^{1 *}$, Ari Tentrem Handayani1 , Budy Wiryono² \\ ${ }^{1}$ SMKPP Negeri Mataram, sugiartarenim@gmail.com \\ ${ }^{2}$ Teknik Pertanian, Universitas Muhammadiyah Mataram
}

\section{INFO ARTIKEL}

RiwayatArtikel:

Diterima: 04-01-20

Disetujui: 25-02-20

\section{Kata Kunci:}

Program PWMP

Purposive Sampling

SMKPPN Mataram

\section{ABSTRAK}

Abstrak: Pembangunan bidang pertanian yang berkelanjutan memerlukan pengembangan kewirausahaan dan juga kompetensi. Salah satu program pendidikan kewirausahaan pada siswa Pembangunan Pertanian yang dilihat adalah program dari Badan Penyuluhan dan Pengembangan Sumberdaya Manusia Pertanian (BPPSDMP) Kementerian Pertanian Republik Indonesia, yaitu Program Wirausaha Muda Pertanian (PWMP). Penelitian ini bertujuan untuk mengevaluasi pelaksanaan program PWMP di SMKPP Negeri Mataram. Metode yang digunakan dalam penelitian ini adalah metode survey dengan jenis penelitian deskriptif analisis. Penelitian dilaksanakan pada bulan April - Juni 2019. Populasi penelitian ini adalah siswa SMKPP Negeri Mataram kelompok penerima Program Wirausaha Muda Pertanian (PWMP), dengan teknik pengambilan sampel secara purposive sampling maka sampel dalam penelitian ini sebanyak 18 orang. Pengumpulan data meliputi studi pustaka dan penelitian lapangan dengan cara observasi dan wawancara. Teknik analisis data yang digunakan adalah analisis deskriptif dengan dukungan tabel frekuensi dan garis interval untuk intepretasi kategori. Hasil penelitian ini menunjukkan bahwa; (1). Evaluasi pelaksanaan PWMP di SMKPP N Mataram berada pada kategori baik, (2). Tahap evaluasi yang dilakukan berupa penyusunan business plan dan pendampingan masuk dalam kategori baik dan sangat baik, (3). Masih terdapat kendala dalam program PWMP yakni pengelolaan waktu dan keamanan usaha.

Abstract: The development of sustainable agriculture requires the development of entrepreneurship and also competence. One of the entrepreneurship education programs for Agricultural Development students seen was a program from the Agricultural Human Resource Extension and Development Agency (BPPSDMP) Ministry of Agriculture of the Republic of Indonesia, namely the Agricultural Young Entrepreneurship Program (PWMP). The study entitled "Evaluation of PWMP Program Implementation in SMKPP N Mataram State" aims to evaluate the implementation of the PWMP program at SMKPP N Mataram State. The method used in this study is a survey method with the type of descriptive analysis research. The study was conducted in April - June 2019. The population of this study was the students of the Mataram State Vocational School, the recipient group of the Agricultural Young Entrepreneur Program (PWMP), with a purposive sampling technique, the sample in this study was 18 people. Data collection includes library research and field research by observation and interviews. The data analysis technique used is descriptive analysis with the support of frequency tables and interval lines for category interpretation. The results of this study indicate that; (1). Evaluation of PWMP program implementation in SMK PP Mataram State is in good category. (2). The evaluation phase carried out in the form of business plan preparation and assistance is included in both good and very good categories. (3). There are still obstacles in the PWMP program, which are time management and business security. 


\section{A. LATAR BELAKANG}

Kewirausahaan atau "entrepreneurship" makin dirasakan urgensinya saat ini. Bukan hanya untuk bisnis, tapi juga untuk berbagai bidang kehidupan. Bangsa Indonesia saat ini sangat membutuhkan banyak entrepreneur di berbagai bidang dan wilayah kerja, apakah Business Entrepreneur yang berkaitan dengan dunia usaha, Academic Entrepreneur yang berkaitan dengan pendidikan, Social Entrepreneur atau wirausaha kemasyarakatan dan Government Entrepreneur yang berkaitan dengan urusan pemerintahan [1].

Menurut Ciputra, suatu bangsa akan maju bila memiliki jumlah entrepreneur (wirausahawan) minimal dua persen dari total jumlah penduduk. Ciputra mencontohkan Singapura memiliki wirausahawan sekitar 7,2 persen, dan Amerika Serikat memiliki 2,14 persen entrepreneur. Kemajuan ekonomi Cina antara lain ditunjang oleh para wirausahaan yang jumlahnya mencapai 20 persen dari penduduk.

Minat masyarakat Indonesia menjadi pengusaha memang masih rendah. Terlihat dari jumlah wirausaha baru yang tumbuh baru sekitar 0,7 persen dari jumlah penduduk yang ada. Masih kalah jauh dibanding negara tetangga, seperti Singapura yang sudah mencapai 7,2 persen, Malaysia 2,1 persen, Thailand 4,1 persen, Korea Selatan 4 persen, dan Amerika Serikat 11,5 persen.

Oleh karena itu, untuk menumbuhkan minat berwirausaha, khususnya di kalangan pemuda, perlu dilakukan pembinaan mental wirausaha, membuka kesempatan berwirausaha seluas-luasnya, dan mempermudah akses terhadap permodalan. Untuk mendukung program tersebut diperlukan pelatihan, pembinaan, dan pembimbingan dalam bentuk magang supaya para pemuda calon wirausaha merasakan kemudahan dalam menciptakan dan merintis usaha yang menguntungkan [2].

Sejak tahun 2015 Kementerian Pertanian RI melalui Badan Penyuluhan dan Pengembangan Sumberdaya Manusia Pertanian (BPPSDMP) menggagas program kewirausahaan pemuda melalui Program Wirausaha Muda Pertanian (PWMP), kini program PWMP yang menyasar mahasiswa dan alumni Polbangtan, Siswa SMK PP/SMK Pertanian, Alumni Perguruan Tinggi Pertanian dan generasi muda lainnya ini telah diberikan kepada 1.015 kelompok PWMP [3].

Penumbuhan pelaku usaha dan pelaku utama pertanian sudah seharusnya menyasar kepada generasi millenial usia produktif. Hampir 33 persen jumlah penduduk yang usianya 15-40 tahun dan tergolong millenial. Kalau jumlah petani sekitar 34 juta jiwa berarti ada 11 ribuan jiwa petani yang bisa di-create menjadi petani muda.

Secara nasional, bonus demografi di Indonesia juga bisa dimanfaatkan menjadi potensi menumbuhkan pelaku usaha maupun pelaku utama bidang pertanian (agropreneur). Perkembangan IPTEK sangat cepat dan dihadapi dgn revolusi industri 4.0. Ada bonus demografi, jumlah pemuda 80 juta dan di Pondok Pesantren saja ada 4-6 juta.Ini bonus demografi yang luar biasa, mari sama-sama wujudkan generasi millenial agropeneur yang profesional. Karena itu, perlunya gerakan penumbuhan generasi muda milenial di bidang pertanian yang adaptif terhadap perkembangan teknologi dan informasi. Salah satunya adalah dengan Program Wirausaha Muda Pertanian (PWMP).

PWMP adalah upaya penumbuhan dan peningkatan minat, keterampilan dan jiwa kewirausahaan generasi muda di bidang pertanian khususnya mahasiswa/alumni Polbangtan, siswa SMK-PP, dan alumni perguruan tinggi pertanian melalui sinergi dengan 29 perguruan tinggi Mitra di bawah koordinasi Polbangtan.

Program kewirausahaan tersebut bertujuan untuk (1) Penyadaran, penumbuhan, pemandirian, dan pengembangan minat, keterampilan dan jiwa kewirausahaan generasi muda di bidang pertanian, (2) Mengembangkan peluang bisnis bagi lulusan sehingga mampu menjadi job-creator di sektor pertanian (agribisnis), (3) Mendorong pertumbuhan dan perkembangan kapasitas lembaga penyelenggara pendidikan pertanian sebagai center of agrisociopreneur development berbasiskan inovasi agribisnis.

Kini kelompok dan produk PWMP tersebut sudah terkenal secara nasional. "Ke depan generasi millenial agropreneur harus profeesional mandiri berdaya saing dengan berbasis teknologi. SMK PP Negeri Mataram sebagai salah satu sekolah kejuruan penerima program PWMP selama 3 (tiga) tahun, sejak tahun 2018 sampai dengan tahun 2020. Tentunya program tersebut harus berjalan sesuai dengan tahapan yang telah ditetapkan yakni tahap penyadaran, tahap pengembangan, dan tahap kemandirian. Ketiga tahapan diperlukan komitmen pimpinan dan seluruh komponen pengelola Polbangtan dan SMK PP di Indonesia yang menerima dana bantuan tersebut.

Berdasarkan realitas tersebut, maka telah dilakukan penelitian tentang "Evaluasi Pelaksanaan Program PWMP di SMK PP Negeri Mataram”.

\section{B. METODE PENELITIAN}

Metode yang digunakan dalam penelitian ini adalah metode survey dengan jenis penelitian deskriptif analisis. Penelitian dilaksanakan pada bulan April - Juni 2019. Populasi penelitian ini adalah siswa SMKPP Negeri Mataram kelompok penerima Program Wirausaha Muda Pertanian (PWMP), dengan teknik pengambilan sampel secara purposive sampling maka sampel dalam penelitian ini sebanyak 18 orang. Pengumpulan data meliputi studi pustaka dan penelitian lapangan dengan cara observasi dan 
wawancara. Teknik analisis data yang digunakan adalah analisis deskriptif dengan dukungan tabel frekuensi dan garis interval untuk intepretasi kategori [4].

\section{HASIL DAN PEMBAHASAN}

\section{Profil SMK PP Negeri Mataram}

Sekolah Menengah Kejuruan Pertanian Pembangunan (SMKPP) Negeri Mataram merupakan kelanjutan dari Sekolah Pertanian Pembangunan (SPP) yang sebelumnya bernama Sekolan Pertanian Menengah Atas (SPMA) yang diresmikan berdirinya pada tanggal 7 November 1955. Perubahan nama menjadi SMKPPN Mataram (pada tahun 2011) sesuai Kesepakatan Bersama Mendiknas RI dan Menteri Pertanian RI Nomor : M.220/7/2008 \& 1018/Kpts/Ho4/VII/KB/2008 Tentang Pembinaan Pendidikan Menengah Kejuruan pada Sekolah Pertanian Pembangunan dan surat edaran [5].

Pada mulanya sejak awal didirikan, SPMA/SMKPP Mataram merupakan salah satu UPT BPSDMP Kementerian Pertanian RI. Sejak tahun 2002 seiring dengan semangat otonomi daerah, kelembagaan SMKPP Mataram beralih menjadi salah satu UPTD Pemerintah Provinsi NTB pada Dinas Pertanian Provinsi NTB. Berdasarkan Pergub nomor :10/2011 tanggal Desember 2011, mulai awal tahun 2012 SMKPP Negeri Mataram menjadi UPTB, Bakorluh Provinsi NTB.

Sebagai salah satu unit pelaksana teknis yang mengemban misi pendidikan bidang pertanian, seluruh proses pendidikan dilaksanakan untuk melahirkan Sumber Daya Manusia menengah terampil dibidang pertanian dalam arti luas, berwawasan global sehingga mampu mengisi dan memenuhi peluang kerja baik didalam maupun luar negeri serta dapat mandiri dengan melaksanakan kegiatan usaha sendiri; membuka lapangan kerja.

Untuk mewujudkan hal di atas, sekolah dalam melakukan proses pendidikan. Kegiatan belajar mengajar harus sesuai dan memenuhi standar yang telah ditetapkan dalam PP Nomor 19 /2005, tentang Standar Nasional Pendidikan (SNP) yang disempurnakan dengan PP/2012

Pemenuhan SNP bagi suatu sekolah merupakan suatu keharusan oleh karena itu disamping peningkaan kualitas kegiatan rutin, penguatan kelembagaan, pemenuhan sarana prasarana, peningkatan kualitas proses untuk peningkatan kompetensi siswa serta peningkatan kapasitas pendidik dan tenaga kependidikan menjadi prioritas disamping kegiatan lainnya.

Sesuai arahan dari Kementerian Pertanian bahwa semua lembaga instansi yang mendapatkan dukungan dari kementerian Pertanian diminta berperan untuk turut mensukseskan empat sukses
Kementerian pertanian dengan mengambil peran sesuai bidangnya dan tupoksinya masing-masing. Berdasarkan arahan tersebut, maka SMK PP N Mataram telah mengajukan Program SMARTS-BE sebagai bagian dari empat sukses Kementan RI.

\section{Pelaksanaan Program PWMP di SMK PP N Mataram}

Penumbuhan Wirausahawan Muda Pertanian (PWMP) menjadi program andalan Kementerian Pertanian (Kemtan) dalam rangka regenerasi petani. Ke depan, generasi muda pertanian bukanlah pekerja bidang pertanian, tetapi menjadi pelaku usaha pertanian.

PWMP merupakan kegiatan Kementan untuk mewujudkan regenerasi petani, yang dirancang untuk mengembangkan peluang bisnis bagi pemuda dan sarjana pertanian mampu menjadi job creator atau pencipta lapangan kerja di sektor pertanian khususnya subsektor agribisnis.

Kementerian Pertanian menerapkan berbagai strategi untuk meningkatkan minat pemuda dan sarjana mendukung pembangunan sektor pertanian. Strategi awal adalah mengubah stigma tentang pertanian bukan hanya budi daya tanaman padi di sawah melainkan pengembangan sektor agribisnis dari subsistem hulu sampai hilir yang membuka peluang kerja dan peluang usaha.

Diikuti strategi menumbuhkembangkan jiwa kewirausahaan di bidang pertanian agar para lulusan perguruan tinggi dari fakultas pertanian lebih menjadi pencipta lapangan kerja atau job creator.

Guna menjalankan strategi tersebut, diperlukan suatu program melalui pelatihan, program magang, kegiatan pembinaan, dan bimbingan agar mereka mengetahui kemudahan dalam menciptakan dan merintis usaha yang menguntungkan, sehingga mereka pun terdorong untuk menjadi wirausahawan muda pertanian (agrosociopreneur) yang mampu menggerakkan dan menciptakan lapangan kerja di sektor pertanian.

Untuk menumbuhkan minat berwirausaha, khususnya di kalangan pemuda perlu dilakukan pembinaan mental wirausaha, membuka kesempatan wirausaha seluas-luasnya, dan mempermudah akses mereka terhadap permodalan.

Program PWMP dirancang untuk menjadikan lembaga pendidikan sebagai center of agripreneur development berbasis inovasi agribisnis dengan bantuan modal usaha kepada pelajar/mahasiswa yang konsen terhadap dunia usaha pertanian.

PWMP dilaksanakan dalam empat tahap selama tiga tahun yang dibagi menjadi tahap penyadaran di tahun pertama, tahun kedua untuk pengembangan dan tahun ketiga untuk tahap kemandirian, dan pada akhirnya, seluruh peserta PWMP akan 
diberikan penghargaan sebagai pelaku wirausahawan muda di bidang pertanian.

Tahap pertama, dimulai dari penyadaran dan penumbuhan minat dan bakat, ini merupakan tahapan awal dengan melakukan program penyadaran akan pentingnya kewirausahaan pemuda. Tahapan awal ini juga merupakan tahapan untuk memberikan motivasi membentuk sikap dan mental serta semangat untuk berwirausaha, menggali ide-ide dan minat untuk berusaha yang sesuai dengan bakat dan potensi yang dimiliki, dan mulai merumuskan perencanaan usaha yang akan dikembangkan berdasarkan ide-ide yang sudah muncul. Selanjutnya tahap kedua, mengembangkan usaha yang dimulai dari Rencana usaha yang telah dibuat baik secara rinci maupun global, tertulis maupun tidak tertulis selanjutkan akan diimplementasikan dalam pelaksanaan usaha.

Rencana usaha akan menjadi panduan bagi pelaksanaan usaha yang akan dilakukan seorang wirausahawan. Dalam kegiatan implementasi rencana usaha, seorang wirausahawan akan mengerahkan berbagai sumber daya yang dibutuhkan seperti modal, material dan tenaga kerja untuk menjalankan kegiatan usaha. Setelah itu tahap ketiga, yaitu tahap pemandirian, dimana keadaan ketika kelompok mampu memutuskan dan melakukan sesuatu secara bersama dengan anggota kelompoknya. Pada tahapan ini kelompok peserta PWMP memiliki sikap mandiri, hampir selalu bisa mengusahakan keperluan usahanya dan menyelesaikan permasalahan yang dihadapinya.

Kelompok peserta PWMP merupakan alumni Perguruan Tinggi Mitra yang menerima manfaat bantuan operasional sebesar Rp. 35,000,000,-/perkelompok, selanjutnya untuk mahasiswa/i Sekolah Tinggi Penyuluhan Pertanian, dan siswa/i Sekolah Menengah Kejuruan Pertanian Pembangunan menerima manfaat bantuan beasiswa sebesar Rp. 15,000,000,-/per-kelompok.
Pelaksanaan PWMP merupakan proses pengembangan wirausaha yang mana kelompok peserta sudah siap mengembangkan produkproduknya dari segi kualitas dan kuantitasnya. Melalui Tahap Pengembangan Penumbuhan Wirausahawan Muda Pertanian, Generasi Muda Pertanian diberikan kesempatan untuk mengembangkan usahanya dibidang pertanian, peternakan dan perkebunan baik budidaya, pengolahan maupun sampai pemasarannya. Tahap ini diarahkan untuk scaling up start up kemikro, mikro keusaha kecil dan usaha kecil ke menengah melalui proses inkubator, mentoring, coaching, accelerator, kolaborasi, dan partnership. Kemudian, Tahap ini dilakukan melalui bantuan promosi dalam berbagai event dan kesempatan. Untuk tahap pengembangan ini dibutuhkan pendamping dengan kompetensi lebih khusus lagi sebagai coach, certifified trainer, livelihood adviser, ahli klaster dan lain lain.

SMK PP Negeri Mataram saat ini sedang menjalani PWMP tahun kedua 2019 tahap pengembangan dengan dana masing-masing $\mathrm{Rp}$. 15.000.00o untuk 2 kelompok; PWMP Tanaman Hias, dan PWMP Tanaman Buah dan Sayur. Sebelumnya SMK PP Negeri Mataram juga menerima PWMP untuk 2 kelompok; PWMP Penggemukan Kambing dan PWMP Tanaman Kangkung dengan penerimaan masing-masing Rp. 15.000.000,-.

SMK PP Negeri Mataram sebagai salah satu penerima PWMP memiliki kewajiban untuk melaksanakan evaluasi program yang mengacu pada KepMenTan RI Nomor : 10/Kpts/SM.210/I/05/2019 tentang Pedoman Penumbuhan Wirausaha Muda Pertanian dengan mengevaluasi penyusunan Business Plan, pendampingan, dan pelaksanaan usaha. Adapun tahapan evaluasi yang dilakukan untuk ketiga komponen tersebut dapat dilihat pada Tabel 1.

Tabel 1.

Perhitungan Parameter Penyusunan Business Plan

\begin{tabular}{|c|c|c|c|c|}
\hline \multirow{2}{*}{ No } & \multirow{2}{*}{ Langkah-Langkah } & \multirow{2}{*}{ Indikator } & \multicolumn{2}{|c|}{ Pemahaman (\%) } \\
\hline & & & Paham & Tidak \\
\hline \multirow[t]{3}{*}{1} & \multirow[t]{3}{*}{ Pengenalan Terhadap Bisnis } & Bentuk & 60 & 40 \\
\hline & & Potensi & 70 & 30 \\
\hline & & Kendala & 65 & 35 \\
\hline \multirow[t]{2}{*}{2} & \multirow[t]{2}{*}{ Arah Bisnis } & Tujuan & 70 & 30 \\
\hline & & Sasaran & 80 & 20 \\
\hline 3 & Target Bisnis & Klien & 60 & 40 \\
\hline \multirow[t]{8}{*}{4} & \multirow{8}{*}{ Rencana Bisnis } & Misi Bisnis & 83 & 17 \\
\hline & & Ringkasan Efektif & 67 & 33 \\
\hline & & Penawaran Produk atau Jasa & 76 & 24 \\
\hline & & Target Pasar & 80 & 20 \\
\hline & & Marketing Plan & 63 & 37 \\
\hline & & Analisis Industri dan Tingkat Persaingan & 58 & 42 \\
\hline & & Laporan Keuangan & 72 & 28 \\
\hline & & Penawaran & 80 & 20 \\
\hline & & Rerata & 70.28 & 29.72 \\
\hline
\end{tabular}


Berdasarkan data Tabel 1 untuk penyusunan business plan PWMP di SMK PP Negeri Mataram dengan mengacu pernyataan responden maka diperoleh nilai rerata sebesar 70.28 responden memahami tahapan penyusunan business plan (kategori baik) sedangkan 29.72 responden kurang memahami tahapan tersebut. Tentunya hasil tersebut mengindikasikan bahwa proses pendampingan yang dilakukan oleh tim pendamping sekolah yang ditunjuk telah melaksanakan tugas dengan baik sehingga siswa SMK PP Negeri Mataram yang terlibat dalam PWMP memahami secara benar tentang pentingnya menyusun business plan dalam memulai suatu usaha yang baru.

Tahap selanjutnya yang dievaluasi dalam pelaksanaan PWMP adalah tahap pendampingan. Pendamping PWMP ditunjuk oleh Kepala Sekolah untuk mengikuti pelatihan pendamping yang diadakan oleh Kementan RI yang selanjutnya bertugas mendampingi pelaksanaan PWMP di unit masing-masing. Pendamping PWMP di SMK PP Negeri Mataram mendampingi siswa dalam penyusunan business plan, pelaksanaan usaha, sampai penyusunan pelaporan. Dalam hal ini peneliti menanyakan kepada responden terhadap kemampuan pendamping dalam menjalankan tugasnya. Diantaranya, kemampuan memberikan arahan, kemampuan penguasaan materi, dan kemampuan memotivasi. Adapun rangkuman jawaban responden dapat dilihat pada Tabel 2.

Tabel 2.

Perhitungan Parameter Kemampuan Pendamping

\begin{tabular}{|c|l|c|c|}
\hline \multirow{2}{*}{$\begin{array}{c}\text { N } \\
\mathbf{0}\end{array}$} & \multirow{2}{*}{ Deskripsi } & \multicolumn{2}{|c|}{$\begin{array}{c}\text { Kemampuan } \\
\text { (\%) }\end{array}$} \\
\cline { 3 - 4 } & & Ya & Tidak \\
\hline 1 & Kemampuan Memberikan Arahan & 80 & 20 \\
\hline 2 & Kemampuan Penguasaan Materi & 85 & 15 \\
\hline 3 & Kemampuan Memotivasi & 89 & 11 \\
\hline \multicolumn{2}{|c|}{ Rerata } & 84.67 & 15.33 \\
\hline
\end{tabular}

Sumber : data primer diolah

Data dari Tabel 2 menunjukkan bahwa tugas pendamping yang ditunjuk oleh sekolah telah memenuhi kriteria yang diharapkan dimana ditunjukkan nilai rerata kemampuan pendamping sebesar 84.67 termasuk dalam kategori sangat baik.

Tahapan terakhir yang dievaluasi yakni tahap pelaksanaan usaha. Pada tahap ini peneliti mengamati pelaksanaan usaha PWMP yang didanai oleh Kementan RI untuk 4 kelompok.

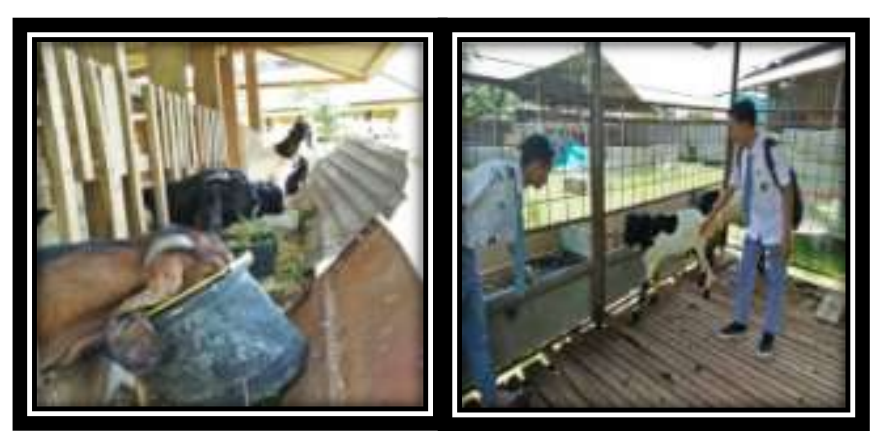

Gambar 1. PWPM Penggemukan Kambing

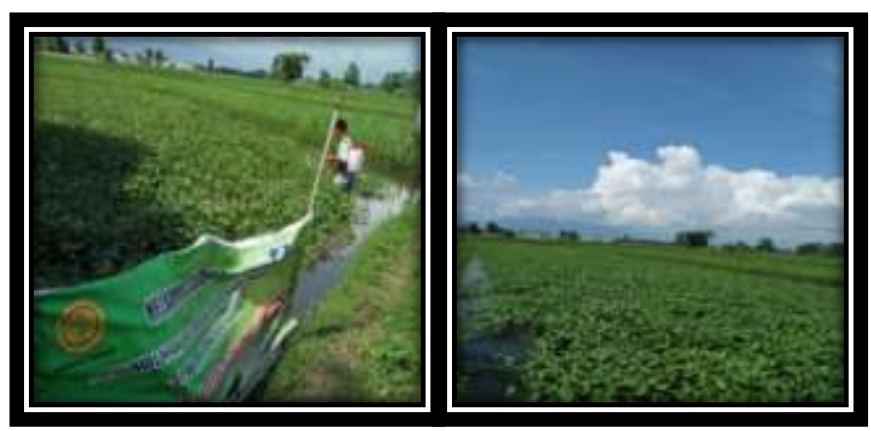

Gambar 2. PWMP Tanaman Kangkung

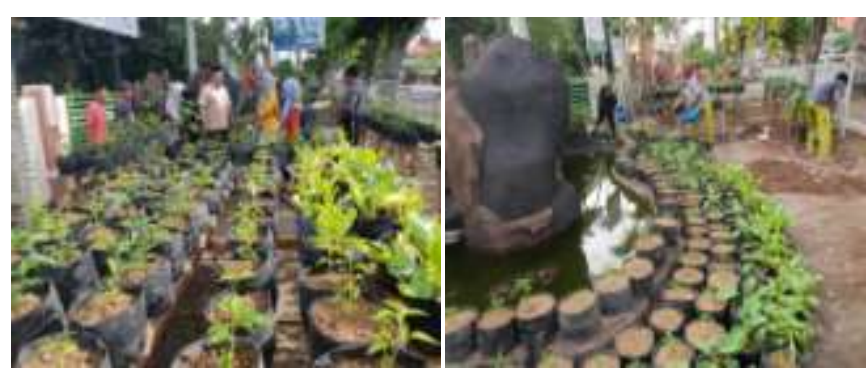

Gambar 3. PWMP Tanaman Buah dan Sayur

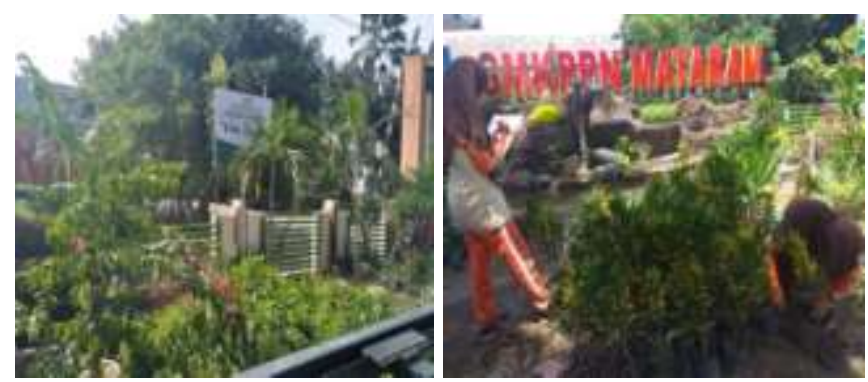

Gambar 4. PWMP Tanaman Hias

Secara umum pelaksanaan PWMP di SMK PP Negeri Mataram berjalan sesuai dengan yang diharapkan hanya ditemukan beberapa permasalahan diantaranya :

1. Diperlukan pengelolaan waktu yang sesuai dengan keterlibatan penuh anggota kelompok PWMP dikarenakan dapat menghambat proses belajar mengajar siswa anggota kelompok.

2. Keamanan usaha perlu ditingkatkan sehingga dapat meminimalisir kerugian usaha.

3. Diperlukan ketekunan dalam usaha untuk mewujudkan kesuksesan. 


\section{SIMPULAN DAN SARAN}

Berdasarkan hasil penelitian dan pembahasan diatas maka diperoleh simpulan sebagai berikut :

1. Evaluasi pelaksanaan program PWMP di SMK PP Negeri Mataram berada pada kategori baik.

2. Tahap evaluasi yang dilakukan berupa penyusunan business plan dan pendampingan masuk dalam kategori baik dan sangat baik.

3. Masih terdapat kendala dalam program PWMP yakni pengelolaan waktu dan keamanan usaha.

\section{DAFTAR RUJUKAN}

[1] Setyobudi, A., Peran Dunia Pendidikan Dalam Mengembangkan SDM Pemuda Dalam Menggerakkan Wirausaha Muda, Makalah Pendidikan Pemuda Koperasi dan Kewirausahaan, 2014.

[2] Syaifullah, C., Generasi Muda Menolak Kemiskinan, Penerbit Cempaka Putih, Klaten, 2009.

[3] Kementerian Pertanian Republik Indonesia. Program PWMP Direktorat BPPSDMP. Jakarta.

[4] Sugiyono, Metode Penelitian Kuantitatif Kaualitatif dan $R$ \& D, Alfabeta, Bandung, 2009.

[5] Sekolah Menengah Kejuruan Pembangunan Pertanian Negeri Mataram, Profil SMK PP Negeri Mataram. Labuapi, 2019. 